\title{
Reflection on the "Excellent Engineers Training Plan" Practical Teaching Establishment of Material Forming and Control Engineering Specialty
}

\author{
Ranfeng Qiu*, Fuxiao Chen, Keke Zhang, Junqing Guo \\ School of Materials Science and Engineering, Henan University of Science and Technology, Luoyang 471039, China \\ *Corresponding author: qiurf1221@163.com
}

\begin{abstract}
According to the requirements of outstanding engineers plans, it is becoming more and more important of practice teaching in the undergraduate course teaching. The paper analyzed the problem in the practice teaching of existing training mode, discussed how to construct the practice teaching system, speed up the pace of engineering education reform base on modern engineering education concept in material forming and control engineering specialty as an example. Find a unique way for engineering innovation and personnel training on personnel training objectives, training model and training practice, which have great significance to deepen the teaching reform, improve the quality of talent training, enhance the capacity of social services.
\end{abstract}

Keywords_Engineering education, Excellent engineers, Discipline characteristics, Training mode

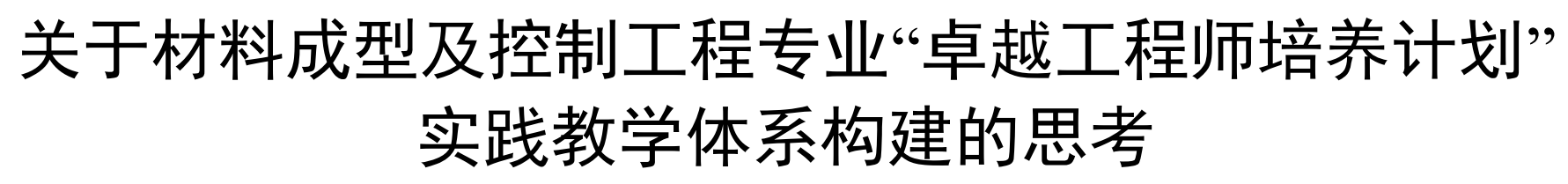

邱然锋* 陈拂晓 张柯柯＼cjkstart郭俊卿

河南科技大学材料科学与工程学院, 洛阳, 河南, 中国

*通讯作者: qiurf1221@163.com

摘 要 按照国家“卓越工程师培养计划”的基本要求, 本科学生实践教学在本科教学中的地位日趋重要。本文通过对现有培养模 式实践教学所存问题进行分析, 结合实施卓越工程师计划的实际需求, 以材料成型及控制工程专业为例, 探索如何构建工程创新人才 培养体系, 加快工程教育改革步伐, 在人才培养目标、人才培养模式、人才培养实践等方面走出独具特色的工程创新人才培养之路。 对深化教学改革, 提高人才培养质量, 增强社会服务能力具有重大意义。

关键词 工程教育, 卓越工程师, 学科特色, 培养模式

\section{1. 引言}

现代工程教育理念起源于美国, 它是伴随美国工程教 育的变革历程而形成的一套完整的指导工程教育改革的理 论体系。中国国家中长期教育改革和发展规划纲要把高校 转变办学理念、调整人才培养目标定位以及改革人才培养 模式, 培养面向工业界、面向未来、面向世界的优秀工程 技术人才提到日程上来。中国高等工科教育突出的问题是

河南省教育科学 “十二五” 规划重点课题(2012-JKGHAB-0034); 河南科技大学教育教学改革重点项目（2014Z-017）支持。
培养的工科学生动手能力、实践能力、分析问题解决问题 的能力薄弱。因此, 以现代工程教育为导向, 建立起以能 力培养为主线, 以工程实践为依托, 以强化工程实践能力、 工程设计能力与工程创新能力为突破口, 理论与工程实践 结合、课内与课外结合、校内与校外结合, 形成与课堂教 学相辅相成又相对独立的实践教学体系是必要的, 也是紧 迫的。

本文依据现代工程教育理念, 针对中国工科教育中存 在的突出问题, 在广泛调研、深入研究的基础上, 对材料 
成型及控制工程专业现行的培养方案的制定、实践教学体 系的构建、工程实践教学基地的打造以及质量保障体系的 规范化进行了探讨。

\section{2. 问题分析}

由于多年的习惯, 更多地强调理论教学, 忽略了实践 教学在工科类专业人才培养中的重要作用, 实践教学的问 题较为突出。

首先, 理论教学与实践教学严重脱节, 理论教学内容 与生产实践内容结合不紧。

其次, 实践教学目的不明确, 主要是为了完成实践教 学“学时数”。实践内容与生产脱离, 只把实习简单地看作 是理论联系实际的一种形式, 偏重于以完成实践教学任务 为目标, 很少考虑实习单位生产、科研、经营的客观需要。

第三, 学校投人实践教学经费较少, 缺乏固定实习场 所, 再加上实习时间不充足, 实习面窄, 内容单一, 实践 教学流于一种形式, 更谈不上对学生创新精神的培养。

第四, 实践教学没有形成科学、规范的实践教学体系, 对实践教学计划、大纲、实习教材、进度、实习评价(师资 考核、学生实习成绩评定等)没有建立科学规范的管理模 式, 无“度”可约, 无“纲”可依。

第五, 实践教学中突出培养学生创新意识和创新能力 不够。对实践教学的过程管理模糊, 对目标管理缺乏科学 的评价体系, 实践教学基地建设、生产实习方式、开放实 验室等方面无法适应对人才培养的要求, 实践教学内容安 排难以适应开放式教学管理和学生个性培养的需求。

\section{3. “卓越工程师培养计划”实践教学体系的构建}

\section{1 面向工程教育, 创新人才培养方案}

培养方案是学校教育教学理念的重要体现, 不仅反映 学校自身的办学定位, 也体现出学校的办学特色和文化底 蕴。河南科技大学材料成型及控制工程专业基于现代工程 教育理念的工程实践培养方案应以现代工程教育理念为基 础, 以材料成型及控制工程专业工程实践教学为研究对象, 发挥学校所在地的地域优势, 以强化工程实践能力、工程 设计能力与工程创新能力为核心, 优化了课程设置, 调整 了教学内容, 增加了企业实践培养环节。并遵循“一条工程 教育主线贯穿始终, 科学教育和工程教育两根脉络并行, 提高工程实践环节学分和校企合作课堂教学两种措施共 推” 的指导思想, 构建了课程体系, 完善了培养方案以着重 培养学生分析问题与解决问题的能力、工程实践能力与创 新能力为目标。

一条工程教育主线贯穿始终, 即把工程教育贯穿工科 学生四年的整个培养过程, 由浅入深, 工程实践的分量逐
年增加, 第四年达到最高。

科学教育和工程教育两根脉络并行, 即在强调工程教 育的同时, 不过多减弱科学教育, 达到科学教育和工程教 育并存。

采取的两项措施, 一是提高工程实践环节学分, 增加 企业理论课程教学环节, 如表 1 和 2 所示实践教学环节的 学分大幅度提高, 由 37 学分提高到 47 学分, 提高了 $27 \%$; 二是校企合作进行课堂教学, 即吸收优秀的企业教师参与 课堂教学, 或把一些专业性强、公艺性强、偏重设备的专 业课程直接放到企业进行, 首次明确了专业课教学、工程 实践教学环节中企业参与教学必须完成的学分数。

表 1 工程实践教学计划进程表

\begin{tabular}{|l|c|c|}
\hline \multicolumn{1}{|c|}{ 实践名称 } & 学分 & 实施学期 \\
\hline 社会实践与企业文化 & 3 & $1 、 2 、 7$ \\
\hline 材料成型工艺设备认知与实践 & 5 & 7 \\
\hline 材料成型工艺案例与设计 & 4 & 7 \\
\hline 工装、模具设计及实践 & 4 & 7 \\
\hline 标准、规范及产品检验 & 3 & 7 \\
\hline 生产运行管理实践 & 3 & $7 、 8$ \\
\hline 材料成型创新实践与毕业设计 & 18 & 8 \\
\hline
\end{tabular}

表 2 企业理论课程教学计划进程表

\begin{tabular}{|c|c|c|c|}
\hline 专业（方向） & 课程名称 & 学分 & 实施学期 \\
\hline \multirow{3}{*}{ 铸造方向 } & 铸造设备及其自动化 & 3 & 7 \\
\hline & 造型材料 & 2 & 7 \\
\hline & 铸造车间规划设计 & 2 & 7 \\
\hline \multirow{3}{*}{ 锻压方向 } & 锻压设备及其自动化 & 3 & 7 \\
\hline & 现代模具制造技术 & 2 & 7 \\
\hline & 锻压节能减排新技术 & 2 & 7 \\
\hline \multirow{3}{*}{ 焊接方向 } & 焊接设备及其自动化 & 3 & 7 \\
\hline & 焊接材料 & 2 & 7 \\
\hline & 焊接车间规划设计 & 2 & 7 \\
\hline
\end{tabular}

根据培养要求和指导思想, 构建了“三课一环节”课程 体系构架。所谓“三课”即通识教育课程、学科平台课程和 专业课程; “一环节“即工程实践环节。以“通识教育课程+ 学科平台课程”支撑学生的科学基础和人文基础, 以“专业 课程”支撑学生的工程实践基础。 


\section{2 科学构建实践教学体系, 突出特色培养}

河南科技大学材料成型及控制工程专业按照“强化基 础、逐步提高、面向工程、突出创新”的工程实践教学体系 改革的基本思路, 构建了如图 1 所示的“三类型八环节”实 践教学体系, 即设置 8 个工程实践教学环节, 可对学生进 行 3 种不同类型的工程实践训练。

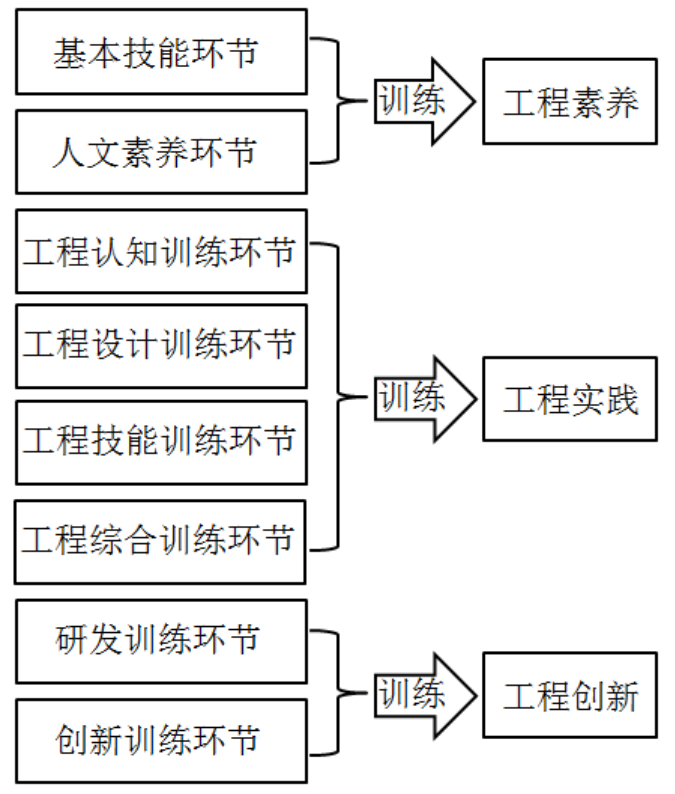

图 1 实践教学体系

(1) 工程素养类训练: 以提高学生科学精神、综合素 质、人文素养、品德修养为主, 培养大学生扎实的理论基 础、初步的科学实验能力、分析问题解决问题的能力、团 队精神和创业意识, 包含基本技能、人文素养两个环节。

基本技能环节: 主要由课程实验组成, 目的是培养学 生求真务实的科学态度、严谨细致的作风, 锻炼分析问题 和解决问题的能力。对于理论性较强的基础课, 主要对课 程中所涉及到的定理、定律进行验证和推导。对于某些专 业基础课和专业课, 主要对课程中的应用成果进行试验。 所有的主干课程均开设综合性实验或设计性实验, 其开设 率在 $85 \%$ 以上。

人文素养环节: 包括社会实践活动、企业文化、企业 管理、生产经营等训练环节。通过举办内容丰富、题材广 泛的人文、社科、艺术及自然科学系列的主题讲座, 通过 深入企业理解企业文化内涵、企业管理模式、生产经营观 念, 使学生在潜移默化中得以熏陶。

(2) 工程实践类训练: 以培养学生分析、解决工程问 题、综合运用学科知识的能力及严谨的科学态度和基本操 作技能为主, 包含工程认知训练、设计训练、技能训练、 综合训练环节。
工程认知训练环节: 为学生构建面向专业生产和工程 应用的训练平台, 受到最基本的工程技术和操作技能方面 的训练。包括金工实习、电工电子实习、工艺技术训练等 环节。学生主要掌握基本工具、各种仪器仪表的使用, 以 及基本操作技能的训练。

工程设计训练环节：根据专业特点, 依照专业所应具 备的能力结构要求进行的设计训练, 主要包括专业课程设 计、工艺设计等环节。课程设计选题结合生产实际, 覆盖 产品设计、工装设计、工艺设计、车间设计等。通过设计 训练使学生识图绘图能力、运用标准能力、工艺分析能力、 结构分析能力和材料选择能力得到提高。

工程技能训练环节: 强化学生对专业知识和工程技能 的认识, 目的是培养学生的专业实践能力和解决实际问题 能力。由专业技能综合训练、生产实习等实践环节构成。 充分利用洛阳市机械制造业基地的优势, 与大中型企业合 作成立校外实践基地, 推进教育教学与生产实际和社会实 践的紧密结合, 为产学研结合教育提供平台, 使学生熟悉 现代化生产技术和装备、生产管理、产品质量控制检测等, 专业技能和专业素养得到显著提高。

工程综合训练环节：根据专业特点, 依照专业所应具 备的能力结构要求进行的专业综合能力训练, 为学生构建 专业能力提升的平台。包括毕业设计 (论文) 等环节。完 善学生毕业设计等实践性教学环节的规范, 选题结合科研 与生产, 使学生动手能力和解决实际问题得到提高。

(3) 工程创新类训练: 以产品、工艺研发和科研训练 为主, 突出学生发现问题、提出问题、解决问题的能力培 养。强化学生的创造性、探索性思维, 包含研发训练、创 新训练环节。

研发训练环节: 目的是对学生进行产品、工艺设计和 科研能力的训练, 包括大学生研究训练计划 (SRTP) 等。 学生在老师指导下进行 SRTP 项目立项, 在一定数额经费 的资助下进行为期一年的研究训练, 使参加学生的实践能 力、创新意识和科研精神得到充分锻炼。通过该项目的实 施, 可进一步发挥学科和师资优势, 解决企业研发人员缺 乏的若境, 建立一批企业研发和学科竞赛训练基地。

创新训练环节: 发挥学生的创新思维和创造性, 使学 生的理论知识得到巩固和升华, 突出学生个性发展, 提高 学生创新能力。包括学生研发和科研立项、科技创新竞赛 (大学生“挑战杯”竞赛、数学建模竞赛、各种专业创新大 赛等) 环节。

\section{3 发挥地域优势, 打造工程实践教学基地群}

建设高质量的工程实践教学基地是推动高校转变教育 思想观念, 改革人才培养模式, 加强实践教学环节, 提升 
高校学生的创新精神、实践能力、社会责任感和就业能力 的关键。目前, 河南科技大学材料成型及控制工程专业依 托学校所在地洛阳先进制造业基地、国家新材料产业基地, 充分发挥大中型骨干企业、科研院所密集、技术力量雄厚、 装备制造业人才多的优势, 探索了工程实践教学中校企合 作运行机制, 搭建了由“2 个国家级工程实践教学基地为依 托、5 个大型企业院所支撑、众多特色鲜明中小企业共助” 的“ $2+5+\mathrm{N}$ ”工程实践教学基地群。

与中信重工机械股份有限公司联合建立了国家重型装 备工程实践教育中心、国家大学生实践教学基地, 为工实 践教学实施提供了平台保障; 与中国一拖集团公司、洛阳 轴承集团有限公司、中铝洛阳铜业有限公司、中船重工 725 研究所、河南柴油机集团有限责任公司等 5 个大型企业院 所建立了实践教学基地, 丰富了实践教学内容, 进一步巩 固了工程实践教学的根基; 与洛阳北方企业集团公司、洛 阳环球模具公司、洛阳市古城铸造厂、洛阳牡丹焊剂厂、 中集凌宇汽车有限公司、有色金属加工设计研究院等众多 特色鲜明的中小企业、研究所建立了校外实践基地, 为校 企合作实践教学的实施拓宽了渠道、增加了专业特色。形 成了一个以材料、工艺、设备为重心, 以分析与设计、工 艺与制造、测试与试验、集成与开发为主线的材料科学与 工程背景下的实践教学基地群。实现了生产、科研及企业 设备直接服务工程教育, 让学生了解、熟悉现代化生产技 术和装备、生产管理、产品质量控制、检测等, 使学生专 业技能和工程素质得到显著提高。

\section{4 规范工程实践环节的要求, 确保培养质量的提高}

河南科技大学材料成型及控制工程专业在深入探讨工 程实践教学的组织、运行、实践规范和质量控制的基础上, 完善了工程实践教学组织、运行、规范和质量控制体系, 并对其中重要的实践环节制定了教学规范与要求, 使学生 能够深入生产一线, 有目的的学习本专业相关的生产准备、 工艺编制、工装设计、生产运行、质量监督、储运调度等
相关实践环节内容, 提高了学生的工程知识和工程素质, 培养了学生的工程综合素质以及交流合作能力, 促进了工 程实践教学的规范化。

为保障工程实践环节的教学质量, 建立了领导听课、 专家评教、同行评教和学生评教的“一听三评”质量评价体 系, 不断反馈听课、评教中存在的问题, 确保实践教学环 节健康运行。

\section{4. 结束语}

基于现代工程教育理念的材料成型及控制工程专业实 践教学体系的构建应以现代工程教育为为导向, 打破基础 课、专业基础课、专业课以知识传授为特征的传统结构, 建立起以能力培养为主线、以工程训练为依托, 以精练理 论教学、强化学生解决实际问题能力为突破口, 理论与工 程实践结合、课内与课外结合、校内与校外结合。形成与 课堂教学相辅相成又相对独立的实践教学体系, 并根据办 学特色对其中的重要实践环节提出规范性要求。

\section{参考文献(References)}

[1] Cui Yuan. Training mode for excellence engineers based on the discipline characteristics. Meitan Higher Education, 2011, 29(1): 66-68.

[2] Lin Jian. The development of general standards for "A Plan for Educating and Training Outstanding Engineers". Researches in Higher Education of Engineering, 2010, (4): 21-29.

[3] Wang Shufang. Practice of the“ $3+2$ "Program and Enlightenment on the"Plan for Educating and Training Outstanding Engineers". Higher Education Forum, 2011, (5): 74-77

[4] Ranfeng Qiu, Keke Zhang, Fuxiao Chen, Junqing Guo. Training mode for excellence engineers based on the discipline characteristics, Education and Education Management, 2013, 29 : 120-125. 